08

\title{
Исследование влияния водородного травления поверхности SiC на последующий процесс формирования пленок графена
}

\author{
() С.П. Лебедев, ${ }^{1}$ И.С. Бараш, ${ }^{1}$ И.А. Елисеев, ${ }^{1}$, П.А. Дементьев, ${ }^{1}$, А.А. Лебедев, ${ }^{1,2}$, П.В. Булат ${ }^{3}$ \\ ${ }^{1}$ Физико-технический институт им. А.Ф. Иофрфе, \\ 194021 Санкт-Петербург, Россия \\ ${ }^{2}$ Санкт-Петербургский государственный электротехнический университет, \\ 197376 Санкт-Петербург, Россия \\ ${ }^{3}$ Университет ИТМО, \\ 197101 Санкт-Петербург, Россия \\ e-mail: lebedev.sergey@mail.ioffe.ru
}

Поступило в Редакцию 25 мая 2019г.

В окончательной редакции 25 мая 2019г.

Принято к публикации 10 июня 2019г.

Изучено влияние температуры и длительности травления поверхности $4 H-\mathrm{SiC}(0001)$ в водороде на структурное совершенство пленок графена, выращиваемых методом термодеструкции. Определено несколько технологических режимов, позволяющих осуществлять травление подложки без изменения стехиометрического состава поверхности. Продемонстрировано, что предростовое травление в водороде при $T=1600^{\circ} \mathrm{C}$ и длительности $1 \mathrm{~min}$ позволяет получать более однородный и структурно-совершенный графен, чем травление при $T=1300^{\circ} \mathrm{C}$ и длительности $30 \mathrm{~min}$.

Ключевые слова: графен, карбид кремния, спектроскопия комбинационного рассеяния света, атомносиловая микроскопия

DOI: 10.21883/JTF.2019.12.48495.217-19

\section{Введение}

Известно, что термодеструкция поверхности монокристаллического карбида кремния $(\mathrm{SiC})$ в среде аргона является одной из наиболее перспективных технологий получения пленок графена большой площади и высокого структурного совершенства [1]. При этом качество получаемого графена сильно зависит не только от структурного совершенства материала подложки, но и от качества обработки поверхности. Для подготовки поверхности современных коммерческих подложек $\mathrm{SiC}$ применяется технология химико-механической полировки (ХМП) [2]. Данная технология представляет собой комбинацию химических и механических способов обработки поверхности подложки. ХМП позволяет получать более гладкую поверхность подложки чем обычная механическая полировка, однако даже после такой обработки на поверхности подложки остается нарушенный слой с повышенным количеством структурных дефектов. Данный нарушенный слой имеет меньшую устойчивость к высокотемпературному нагреву, чем подложка с нормальной структурой, что в свою очередь может привести к неконтролируемой сублимации компонентов $\mathrm{SiC}$ c поверхности подложки и образованию неоднородной по толщине и структурному совершенству графеновой пленки.

Одним из возможных методов дополнительной обработки поверхности коммерческих подложек $\mathrm{SiC}$ является травление в атмосфере водорода при высоких температурах [3]. Такая обработка позволяет удалить структурные дефекты, оставшиеся после механической обработки и получить поверхность, структурированную регулярными атомно-гладкими ступенями [4,5]. Было показано, что таким образом можно обрабатывать поверхность различных политипов $\mathrm{SiC}$ [6]. В то же время отмечалось, что длительное травление в водороде поверхности $\mathrm{SiC}$ подложки приводит к увеличению плотности структурных дефектов в эпитаксиальном слое, выращенном на основе данной подложки [7].

Для качественной подготовки поверхности коммерческих подложек карбида кремния при помощи водородного травления необходимо подобрать комбинацию технологических условий, позволяющих удалить нарушенный приповерхностный слой и получить качественную поверхность подложки без изменения стехиометрии $\mathrm{SiC}$. Целью настоящей работы был поиск оптимального режима травления поверхности $\mathrm{SiC}$ в атмосфере водорода и исследование влияния данного травления на структурное совершенство выращиваемой на этой поверхности пленки графена.

\section{1. Эксперимент}

В качестве подложки применялись высокоомные коммерческие пластины $4 \mathrm{H}$-SiC. Для проведения исследований по травлению в атмосфере водорода и последующему росту графена была выбрана поверхность с ориентацией (0001) (Si-грань) подложки $\mathrm{SiC}$, поскольку 
на данной поверхности формируется более равномерная и качественная пленка графена [8].

Для травления поверхности подложки применялась газовая смесь, содержащей аргон (объемная доля 95\%) и водород (объемная доля 5\%). Как известно, аргон является инертным газом, поэтому он не принимает участия в химических процессах, возникающих на поверхности подложки при ее нагреве. Выбор газовой смеси с низким процентом содержания водорода обусловлен соображениями безопасности при проведении экспериментов с нагревом элементов технологической установки до высоких температур во взрывоопасной среде.

Для определения оптимальных технологических условий травления в водороде осуществлялось варьирование основных технологических параметров: температура травления изменялась от 1300 до $1600^{\circ} \mathrm{C}$, время травления - от 1 до $30 \mathrm{~min}$. Давление газовой смеси в ростовой камере (760 Torr) во всех процессах оставалось одинаковым.

Определение степени влияния предростового травления поверхности подложки в водороде на структурное совершенство и однородность выращиваемого графена осуществлялось путем сравнения результатов роста на исходной подложке и на подложке после травления при различных условиях. Рост графена во всех случаях производился при одинаковых технологических параметрах: температура роста $-1750 \pm 20^{\circ} \mathrm{C}$, время роста от $5 \mathrm{~min}$, давление аргона в камере $730 \pm 10$ Torr.

Для контроля состояния поверхности подложки $\mathrm{SiC}$ после травления и после роста графена применялись современные методики характеризации микро- и нанообъектов: атомно-силовая микроскопия (АСМ), Кельвинзондовая микроскопия (КЗМ) и спектроскопия комбинационного рассеяния света (КРС). Метод АСМ применялся для получения карт топографии поверхности. При помощи метода КЗМ определялось распределение поверхностного потенциала образцов. Исследования данными методиками производились с помощью сканирующего зондового микроскопа NtegraAURA (NT-MDT) в атмосферных условиях. Поле сканирования составляло $10 \times 10 \mu \mathrm{m}$. Метод КРС использовался для определения структурного состава поверхности подложки. Измерения методом спектроскопии КРС проводились при комнатной температуре в геометрии „обратного рассеяния“ на спектрометрической установке Horiba JobinYvon T64000, оснащенной конфокальным оптическим микроскопом, который позволяет получать информацию из области графеновой пленки $\sim 1 \mu \mathrm{m}$. При измерениях использовалась длина волны возбуждающего излучения $532 \mathrm{~nm}$; мощность лазерного излучения на образце составляла $\sim 4.0 \mathrm{~mW}$ в пятне диаметром $\sim 1 \mu \mathrm{m}$. Наряду с локальной диагностикой, исследовались площади образцов размером $10 \times 10 \mu \mathrm{m}$ с последующим построением карт КРС различных параметров спектральных линий.

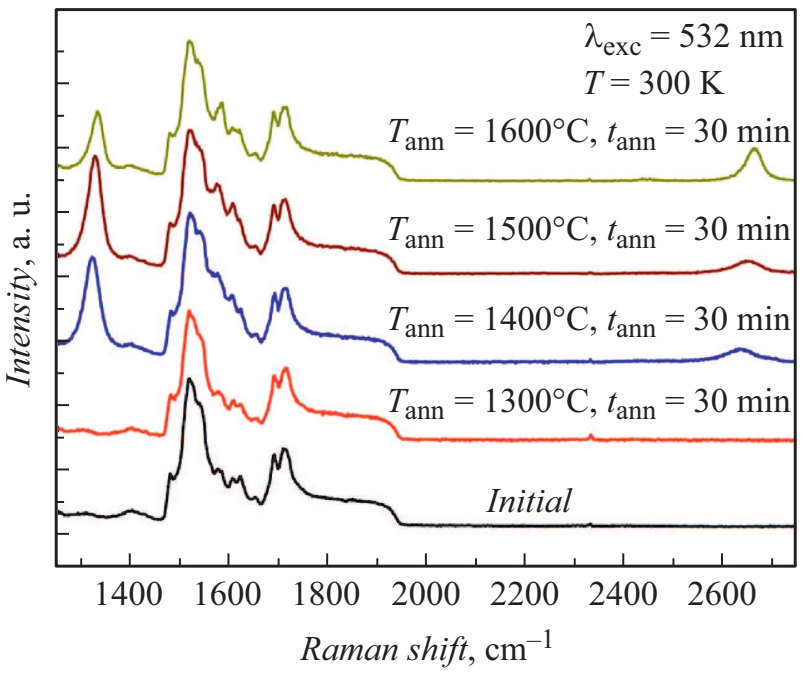

Рис. 1. Спектры КРС, полученные на поверхности подложки $\mathrm{SiC}$ после ее травления в водороде при различных температурах.

\section{2. Результаты измерений и их обсуждение}

На рис. 1 представлен ряд спектров КРС в интервале частот от 1300 до $2800 \mathrm{~cm}^{-1}$, полученных на исходной поверхности $\mathrm{SiC}$ подложки и на поверхности образцов, подвергшихся травлению при различных температурах в газовой смеси, содержащей водород. На спектре КРС, полученном на исходной подложке, видны широкие полосы, соответствующие спектру второго порядка подложки $\mathrm{SiC}$. Спектр КРС образца, отожженного при температуре $1300^{\circ} \mathrm{C}$ в течение $30 \mathrm{~min}$, полностью соответствует спектру исходной подложки, что свидетельствует о сохранившейся на поверхности структуре карбида кремния без изменения стехиометрии. При температуре травления $1400^{\circ} \mathrm{C}$ и выше в спектрах появляются дополнительные пики, соответствующие линиям $D\left(\sim 1350 \mathrm{~cm}^{-1}\right)$ и $2 D\left(\sim 2670 \mathrm{~cm}^{-1}\right)$ в спектрах КРС графена и графита [9], указывающие на изменение стехиометрии поверхности подложки и начало ее графитизации.

Травление поверхности $\mathrm{SiC}$ в среде водорода осуществляется за счет протекания трех процессов на поверхности подложки: диссоциация кристаллической структуры $\mathrm{SiC}$ на компоненты $\mathrm{Si}_{2} \mathrm{C}, \mathrm{SiC}_{2}, \mathrm{SiC}, \mathrm{Si}$ в газообразном состоянии, С в твердом состоянии и др.), испарение газообразных компонентов $\mathrm{SiC}$ с поверхности подложки и протекание химических реакций между водородом и углеродом, оставшимся на поверхности подложки. Подробное описание процесса травления представлено в работе [3]. Как показывает рис. 1 , интенсивность протекания процесса диссоциации при температурах выше $1400^{\circ} \mathrm{C}$ превышает интенсивность химического взаимодействия между водородом и 


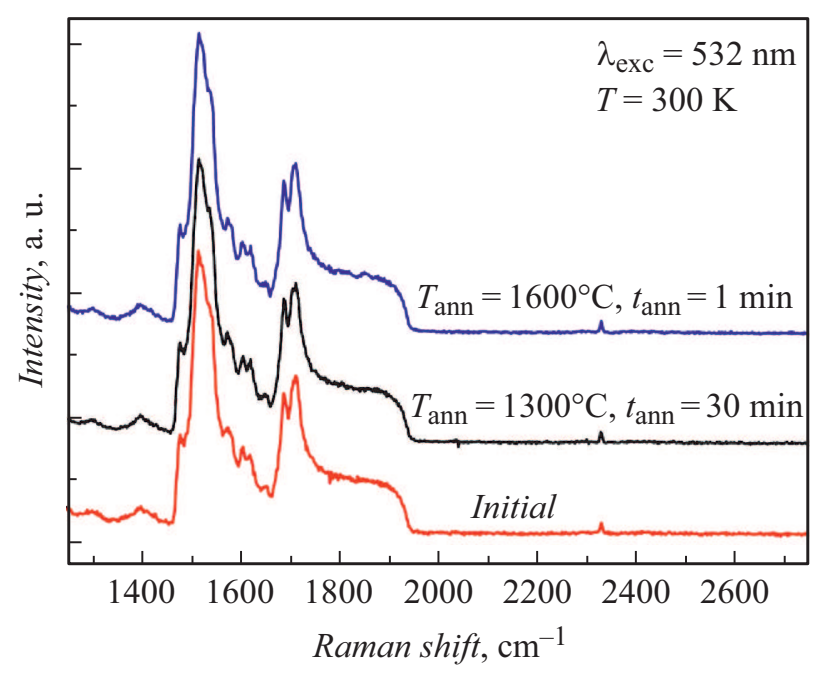

Pис. 2. Спектры КРС образцов без изменения стехиометрии поверхности $\mathrm{SiC}$, полученных путем травления в водороде при различных технологических параметрах.

углеродом из-за низкого процента содержания водорода в газовой смеси.

Поскольку увеличение процентного содержания водорода в газовой смеси нежелательно из соображения безопасности проведения технологического процесса, то единственным вариантом получения чистой $\mathrm{SiC}$ поверхности после травления при высоких температурах остается уменьшение длительности травления. Экспериментальным путем было установлено, что при температуре травления $1600^{\circ} \mathrm{C}$ сохранение исходной структуры $\mathrm{SiC}$ возможно только при длительности травления не более $1 \mathrm{~min}$. На рис. 2 представлены спектры КРС, подтверждающие возможность травления подложек карбида кремния без изменения стехиометрии поверхности при различных технологических параметрах.

На рис. 3 представлены карты топографии поверхности в области сканирования $10 \times 10 \mu \mathrm{m}$, полученные на исходной подложке $\mathrm{SiC}$ и на образцах после травления в водороде при различных технологических режимах. Поверхность исходной подложки после ХМП представляет собой достаточно гладкую равномерную поверхность, величина средней шероховатости поверхности RMS (root mean square) которой составляет $0.5 \mathrm{~nm}$. В процессе травления подложки в водороде при температуре $1300^{\circ} \mathrm{C}$ в течение $30 \mathrm{~min}$ ее поверхность преобразуется в набор атомно-гладких террас шириной $\sim 500 \mathrm{~nm}$, разделенных ступенями высотой $05 \mathrm{~nm}, \mathrm{RMS}$ такой структуры составляет $0.25 \mathrm{~nm}$. Увеличение температуры травления приводит к формированию более широких террас величиной 2-4 $2 \mathrm{~m}$, высота ступени в таком случае составляет $4-8 \mathrm{~nm}$, a $\mathrm{RMS}=2.3 \mathrm{~nm}$.

На рис. 4 представлены карты топографии поверхности в области сканирования $10 \times 10 \mu \mathrm{m}$, полученные на графеновых пленках, выращенных на исходной подложке $\mathrm{SiC}$, и на подложках после водородного травления при различных технологических режимах. Во всех трех случаях поверхность подложки после роста представляет собой серию вытянутых террас, разделенных ступенями, однако ширина террас и высота ступеней сильно различаются. В случае использования исходной подложки для роста наблюдается формирование нерегулярной поверхности, покрытой набором неоднородных по форме террас с различной высотой ступеньки между ними. Среднее значение шероховатости такой поверхности составляет $1.2 \mathrm{~nm}$. Использование предростового водородного травления при $T=1300^{\circ} \mathrm{C}$ и длительности травления $=30 \mathrm{~min}$ позволяет получить более регулярную поверхность с величиной RMS $=1 \mathrm{~nm}$. Однако на поверхности некоторых террас наблюдаются небольшие участки, отличающиеся по высоте от остальной области террасы (имеют более светлый контраст), что свидетельствует о неоднородном процессе диссоциации структуры $\mathrm{SiC}$ на отдельных участках террасы. Увеличение температуры предростового травления до $T=1600^{\circ} \mathrm{C}$ и уменьшение длительности травления до $1 \mathrm{~min}$ позволяет добиться формирования в процессе роста набора регулярных террас с небольшим разбросом по ширине $\sim 200-400 \mathrm{~nm}$ и $\mathrm{RMS}=0.5 \mathrm{~nm}$. Различие в морфологии поверхности после водородного травления и после роста графена обусловлено тем, что для роста используется более высокая температура, при которой может происходить перегруппировка ступеней на поверхности подложки.

В работе [10] описана методика определения толщины графеновой пленки с использованием КЗМ, которая заключается в построении карты распределения потенциала поверхности графеновой пленки. Согласно работе [11], в зависимости от количества графеновых слоев, сформировавшихся в процессе роста, будет меняться поверхностный потенциал графеновой пленки на определенном участке. Например, величина поверхностного потенциала двуслойного графена на 120-140 mV выше, чем монослойного. Если за нулевой потенциал принять потенциал монослойного графена, то области с более толстым слоем на карте распределения потенциала будут иметь более светлый контраст. На рис. 5 представлены карты распределения поверхностного потенциала, полученные на графеновых пленках, выращенных на исходной подложке $\mathrm{SiC}$ и на подложках после водородного травления при различных технологических режимах. Анализ карты на рис. 5, a показывает, что при использовании исходной подложки для роста образуется пленка, которая по площади поверхности более чем на 50\% состоит из двуслойного графена. При этом форма границ между однослойным и двуслойным графеном совпадает с формой некоторых террас на рис. 3, а. Использование предварительного травления при $\mathrm{T}=1300^{\circ} \mathrm{C}$ позволяет снизить количество вставок двуслойного графена до 20$25 \%$. Предварительное травление подложки в водороде при $T=1600^{\circ} \mathrm{C}$ длительностью $1 \mathrm{~min}$ позволяет получить однородную по потенциалу пленку с небольшим процентом включений (5-10\%) двуслойного графена. 
$a$
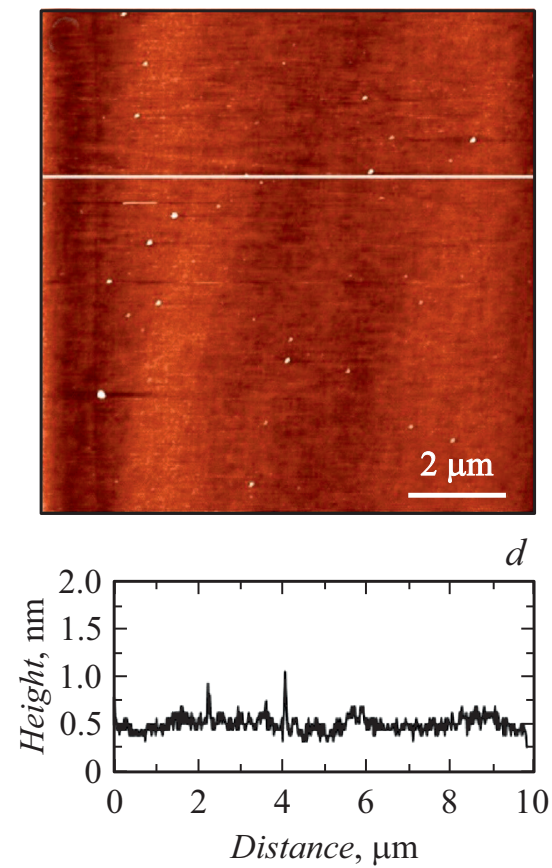

$b$
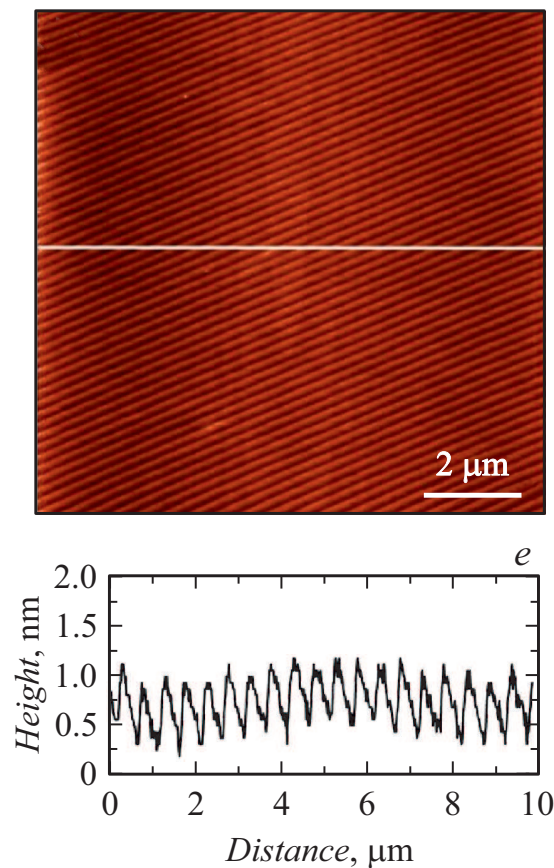

C
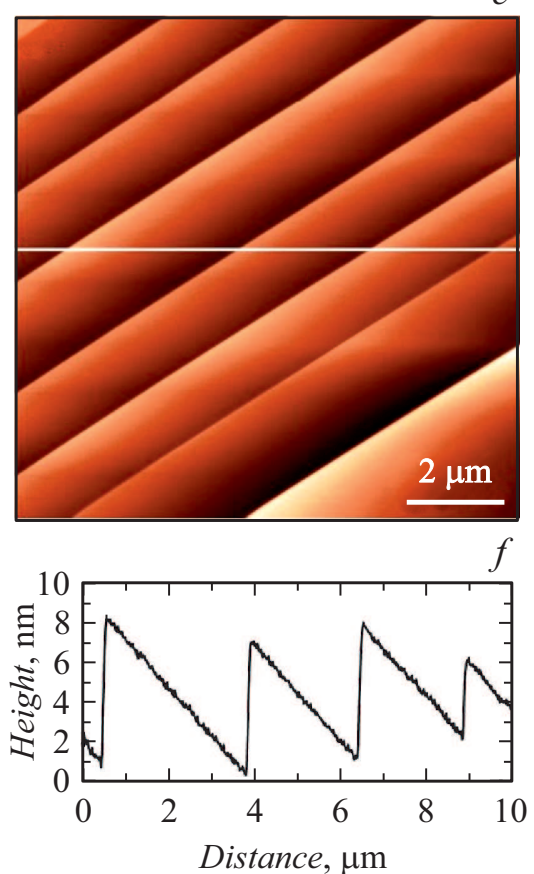

Рис. 3. Топография поверхности исходной подложки $(a)$ и ее профиль, полученный вдоль пунктирной линии $(b)$. Топография поверхности после травления в водороде при $T=1300^{\circ} \mathrm{C}, t=30 \mathrm{~min}(c)$ и ее профиль $(d)$. Топография поверхности после травления в водороде при $T=1600^{\circ} \mathrm{C}, t=1 \min (e)$, и ее профиль $(f)$.
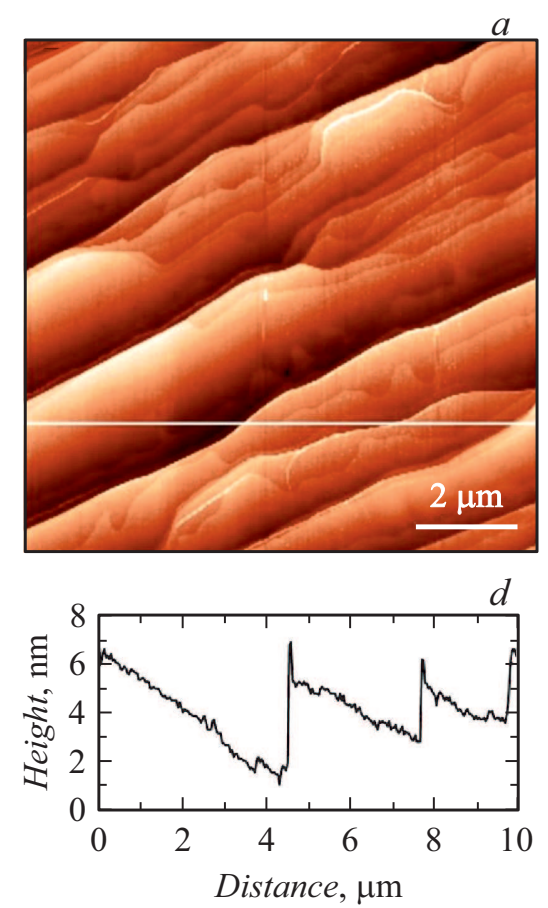
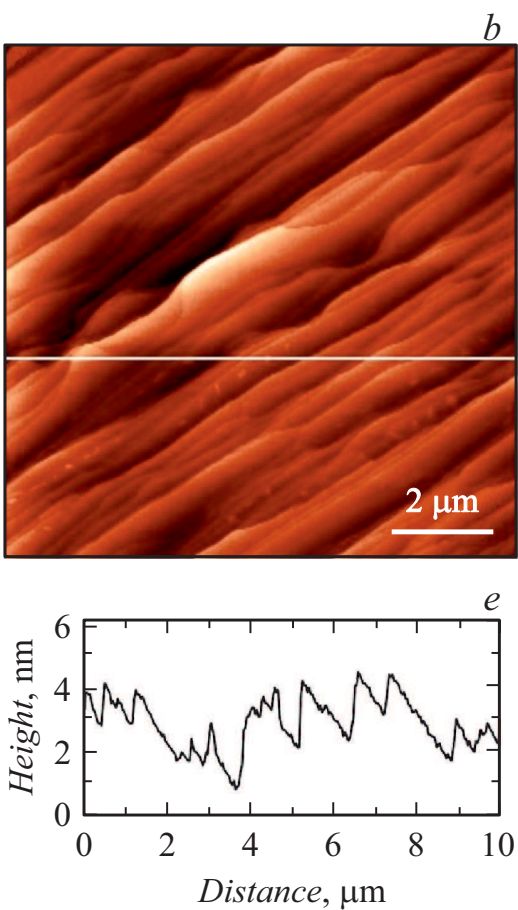
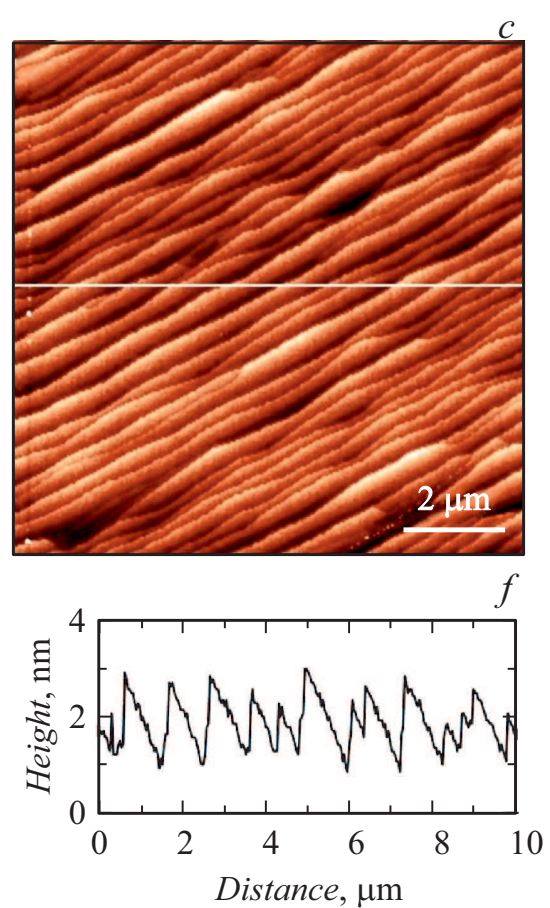

Рис. 4. Топография поверхности подложки после роста графена: $a-$ на исходной подложке, $d-$ соответствующий профиль; $b-$ на подложке после водородного травления при $T=1300^{\circ} \mathrm{C}, t=30 \mathrm{~min}, e-$ eе профиль; $c-$ на подложке после водородного травления при $T=1600^{\circ} \mathrm{C}, t=1 \mathrm{~min}, f$ - ее профиль.

Все три образца, результаты исследования которых методами АСМ и КЗМ представлены выше, были также исследованы методом спектроскопии КРС. Массивы спектров, измеренные на этих образцах на площади $10 \times 10 \mu \mathrm{m}$ с шагом в $1 \mu \mathrm{m}$, представлены на рис. 6 . В спектрах КРС всех трех образцов наблюдаются осо- 

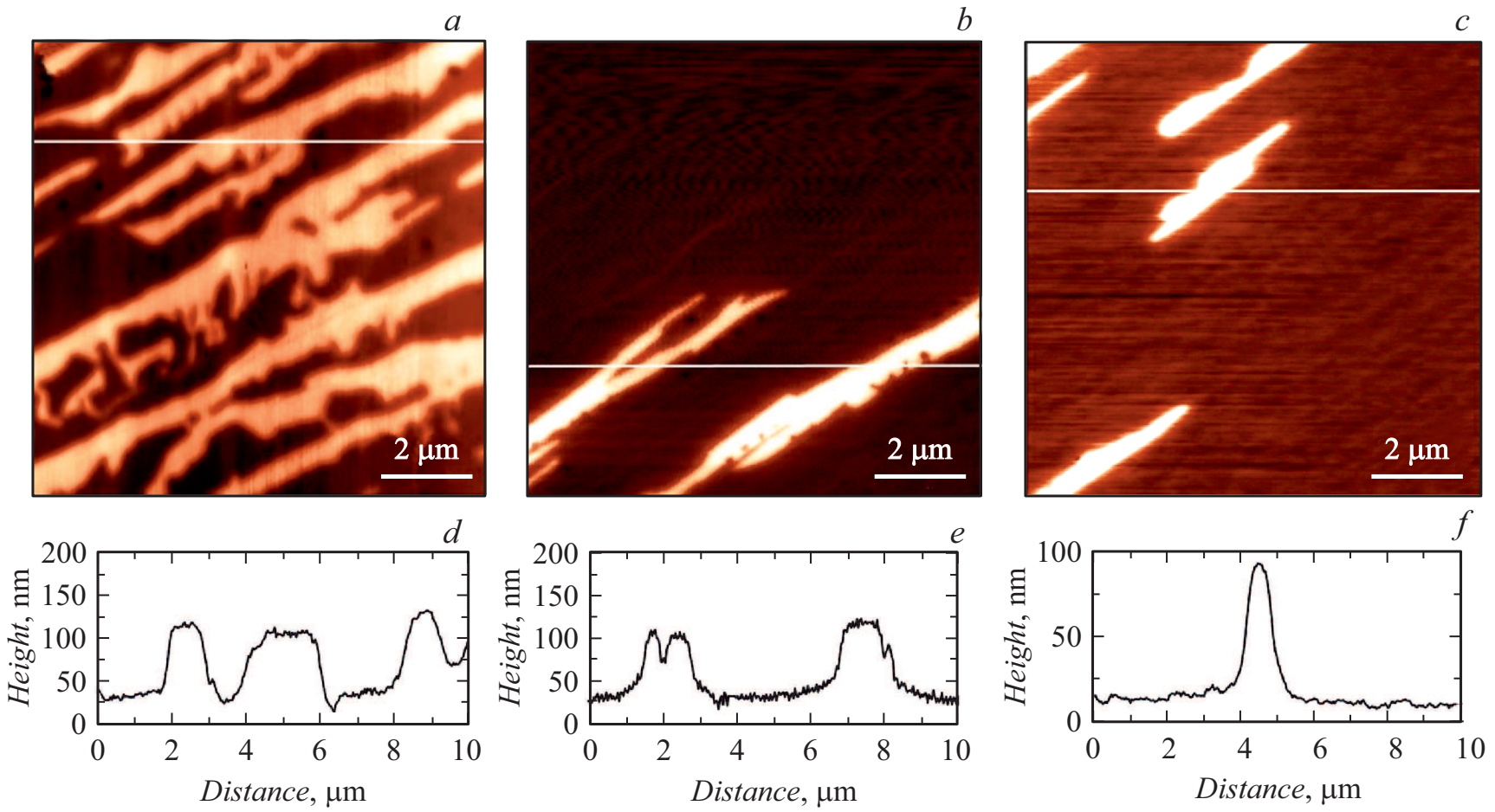

Рис. 5. Карта распределения поверхностного потенциала подложки после роста графена: $a-$ на исходной подложке, $d-$ соответствующий профиль; $b-$ на подложке после водородного травления при $T=1300^{\circ} \mathrm{C}, t=30 \mathrm{~min}, e-$ eе профиль; $c-$ на подложке после водородного травления при $T=1600^{\circ} \mathrm{C}, t=1 \mathrm{~min}, f$ - ее профиль.
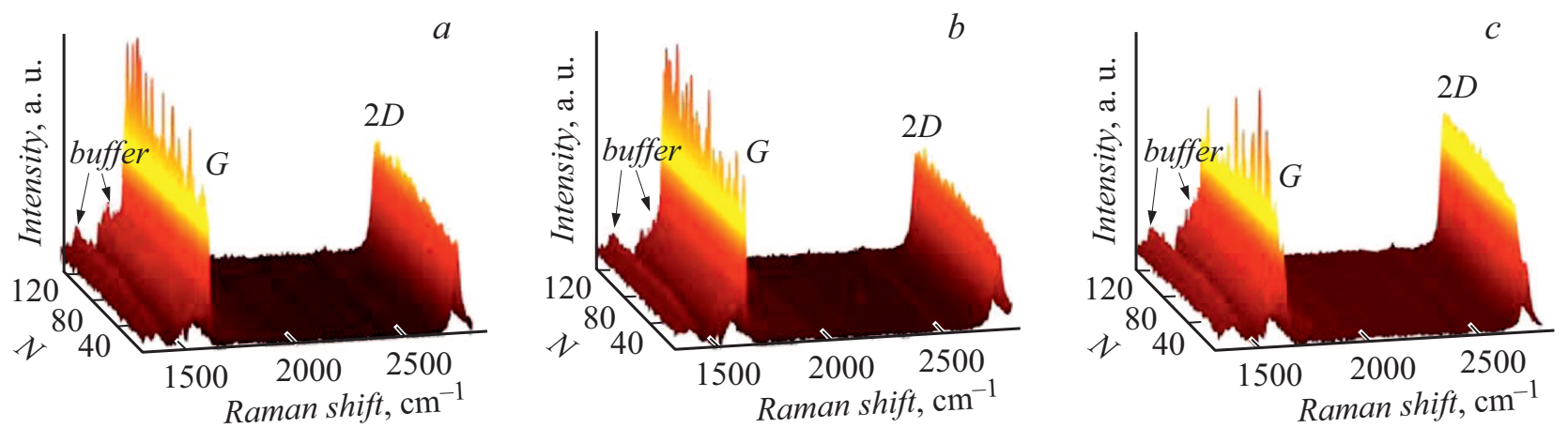

Рис. 6. Массив спектров КРС образцов графена, выращенных на исходной подложке $(a)$, на подложке после водородного травления при $T=1300^{\circ} \mathrm{C}, t=30 \mathrm{~min}(b)$, и на подложке после водородного травления при $=1600^{\circ} \mathrm{C}, t=1 \mathrm{~min}(c)$.

бенности, характерные для графена, выращенного на $\mathrm{Si}$-грани $\mathrm{SiC}$ : линии $G\left(\sim 1600 \mathrm{~cm}^{-1}\right), 2 D\left(\sim 2700 \mathrm{~cm}^{-1}\right)$, а также широкие полосы в области $1300-1550 \mathrm{~cm}^{-1}$, соответствующие буферному слою между графеном и $\mathrm{SiC}$ [12]. На относительно небольшое количество дефектов во всех трех образцах указывает тот факт, что линию $D\left(\sim 1350 \mathrm{~cm}^{-1}\right)$ во всех массивах спектров невозможно выделить из-за ее малой интенсивности по сравнению с интенсивностью спектра буферного слоя. Тем не менее, как будет показано далее, результаты анализа полученных массивов спектров демонстрируют существенные различия между образцами, выращенными на подложках с различными условиями предростовой обработки.
Метод спектроскопии КРС позволяет определять толщину графеновой пленки путем анализа ширины и формы линии $2 D$ в спектре графена. В случае монослойного графена линия $2 D$ имеет симметричную форму и хорошо аппроксимируется контуром Лоренца, в то время как формирование второго слоя приводит к появлению в спектрах КРС уширенной линии $2 D$ асимметричной формы [9]. На рис. 7, $a-c$ представлены карты КРС полной ширины на половине высоты (FWHM) линии $2 D$, полученные при обработке массивов спектров, измеренных на образцах графена, выращенного при различных условиях обработки подложки. На всех трех образцах в областях, где FWHM линии $2 D$ составляла от 30 

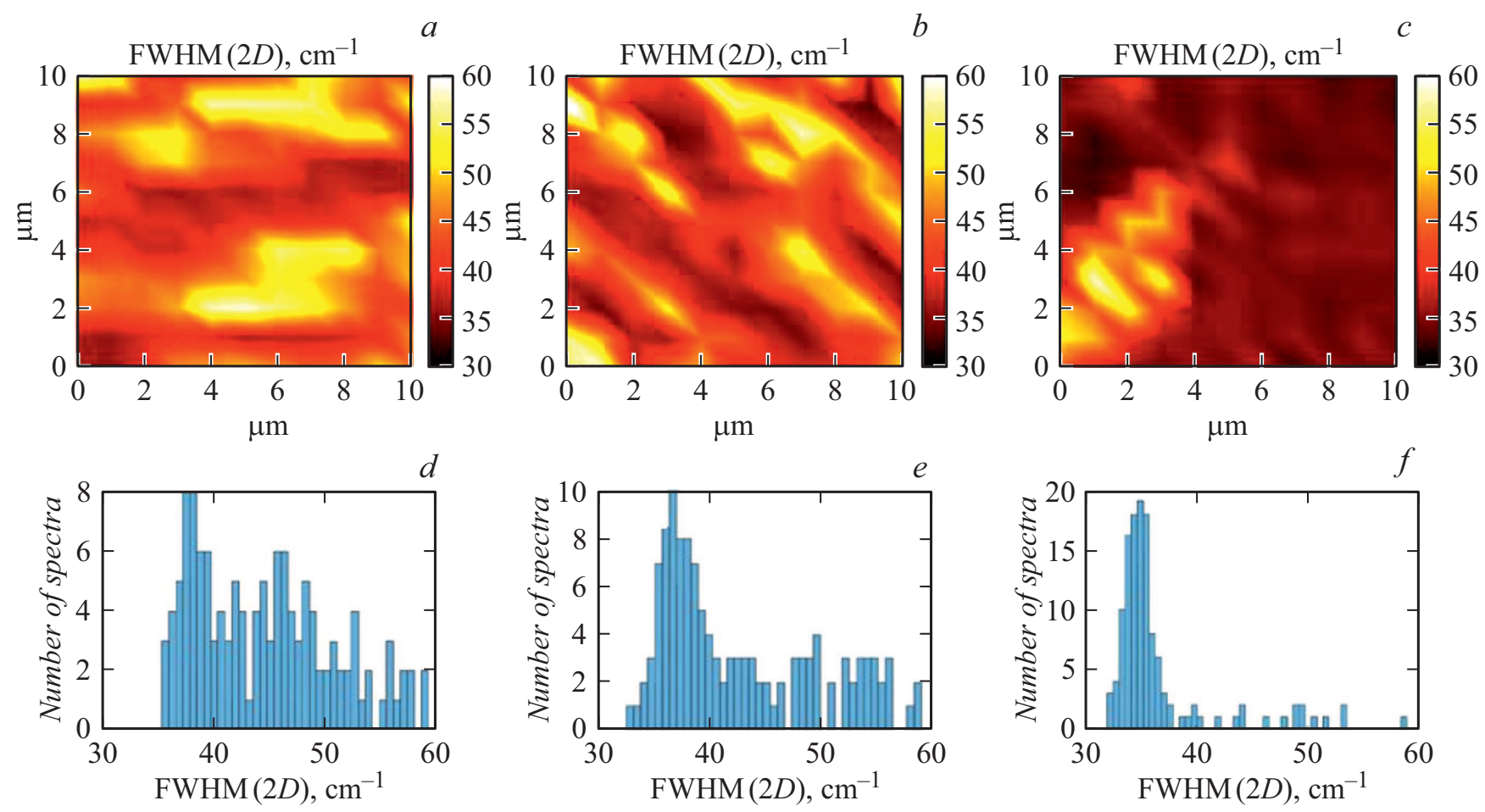

Pис. 7. Карты КРC FWHM линии $2 D$ для образцов графена: $a-$ на исходной подложке, $d-$ соответствующая гистограмма; $b-$ на подложке после водородного травления при $T=1300^{\circ}, t=30 \mathrm{~min} ; e-$ соответствующая гистограмма; $c-$ на подложке после водородного травления при $T=1600^{\circ} \mathrm{C}, t=1 \mathrm{~min}, f$ - соответствующая гистограмма.

до $42 \mathrm{~cm}^{-1}$, ее форма была симметричной, что свидетельствует о наличии в этих областях монослойного графена. В областях, где FWHM была выше $42 \mathrm{~cm}^{-1}$, наблюдалась асимметричная форма линии $2 D$, указывающая на наличие двуслойного графена.

Анализ гистограмм, представленных на рис.7, $d-f$, позволяет оценить долю двуслойного графена в исследуемых образцах. Для образца, выращенного на исходной подложке, доля двуслойного графена, согласно данным КРС, составила 55\%. Предварительная обработка позволила снизить долю двуслойного графена: после травления в водороде при $1300^{\circ} \mathrm{C}$ в течение $30 \mathrm{~min}$ она составила $37 \%$, а повышение температуры травления подложки до $1600^{\circ} \mathrm{C}$ и уменьшение длительности травления до $1 \mathrm{~min}$ уменьшило долю двуслойного графена до $10 \%$.

Таким образом, согласно данным КРС, предростовая обработка подложки в водороде при температуре $1600^{\circ} \mathrm{C}$ в течение $1 \mathrm{~min}$ позволяет достичь наименьшей доли двуслойных включений в графеновых пленках. Данные КРС о процентном соотношении включений двуслойного графена для пленок, выращенных при разных параметрах предростовой обработки подложек, достаточно хорошо совпадают с оценочными данными КЗМ. Небольшие расхождения в оценке вызваны различным разрешением при сканировании поверхности у вышеуказанных методов.

\section{Заключение}

В работе представлены результаты исследования процесса травления поверхности монокристаллического карбида кремния в атмосфере водорода при различных технологических режимах, а также влияние данного травления на качество выращиваемого графена. Получены следующие основные результаты:

1. По итогам серии экспериментов по поиску технологических режимов травления поверхности монокристаллического карбида кремния в газовой смеси, содержащей аргон (объемная доля 95\%) и водород (объемная доля 5\%), определены несколько режимов, позволяющих осуществлять травление поверхности подложки без изменения стехиометрического состава поверхности. Возможность осуществления данного травления при различных технологических параметрах обусловлена уравновешиванием интенсивности процесса диссоциации структуры $\mathrm{SiC}$ при нагреве подложки с интенсивностью реакции водорода и атомов углерода на поверхности подложки.

2. Исследовано влияние процесса травления в водороде при различных технологических условиях на структурное совершенство и однородность графена, выращиваемого методом термодеструкции поверхности $\mathrm{SiC}$. Обнаружено, что травление в водороде при $T=1600^{\circ} \mathrm{C}$ и длительности $1 \mathrm{~min}$ позволяет получать более однородные монослойные графеновые пленки с процентом 
включений двуслойного графена на уровне 5-10\%, чем травление при $T=1300^{\circ} \mathrm{C}$ и длительности $30 \mathrm{~min}$. Очевидно, травление при $T=1600^{\circ} \mathrm{C}$ позволяет сформировать поверхность подложки с более совершенной кристаллической структурой, которая при последующем росте графена обеспечивает равномерную диссоциацию структуры $\mathrm{SiC}$ по площади поверхности с формированием равномерного монослойного покрытия подложки графеном.

\section{Финансирование работы}

Работа выполнена при финансовой поддержке Министерства образования и науки Российской Федерации (Соглашение № 14.575.21.0148, уникальный номер проекта RFMEFI57517X0148).

\section{Конфликт интересов}

Авторы заявляют, что у них нет конфликта интересов.

\section{Список литературы}

[1] Yazdi G.R., Iakimov T., Yakimova R. // Crystals. 2016. Vol. 6. P. 53. DOI: $10.3390 /$ cryst 6050053

[2] Zhou L., Audurier V., Pirouz P., Powell J.A. // J. Electrochem. Soc. 1997. 144. P. 161-163.

[3] Kumagawa M., Kuwabara H. // Jpn. J. Appl. Phys. 1969. Vol. 8. N 4. P. 421-428.

[4] Dogan S., Johnstone D., Yun F., Sabuktagin S., Leach J., Baski A.A., Morkoc H., Li G., Ganguly B. // Appl. Phys. Lett. 2004. Vol. 85. N 9. P. 1547-1549. DOI: $10.1063 / 1.1786632$

[5] Sagar A., Lee C.D., Feenstra R.M., Inoki C.K., Kuan T.S. // J. Appl. Phys. 2002. Vol. 92. N 7. P. 4070-4074. DOI: $10.1063 / 1.1501749$

[6] Frewin Ch.L., Colleti C.C., Riedi Ch., Starke U., Saddow S. // Mater. Sci. Forum. 2009. Vol. 615-617. P. 589-592. DOI: 10.4028/www.scientific.net/MSF.615-617.589

[7] Anzalone R., Piluso N., Salanitri M., Lorenti S., Arena G., Coffa S. // Mater. Sci. Forum. 2017. Vol. 897. P. 71-74. DOI: 10.4028/www.scientific.net/MSF.897.71

[8] Лебедев С.П., Елисеев И.А., Давыдов В.Ю., Смирнов А.Н., Левицкий В.С., Мынбаева М.Г., Кулагина M.M., Hähnlein B., Pezoldt J., Лебедев A.A. // Письма в ЖТФ. 2017. Т. 43. Вып. 18. С. 64-72. DOI: 10.21883/PJTF.2017.18.45035.16895 [Lebedev S.P., Eliseyev I.A., Davydov V.Y., Smirnov A.N., Levitskii V.S., Mynbaeva M.G., Kulagina M.M., Hähnlein B. Pezoldt J., Lebedev A.A. // Tech. Phys. Lett. 2017. Vol. 43. P. 849-852. DOI: $10.1134 / \mathrm{S} 106378501709022]$

[9] Ferrari A.C., Meyer J.C., Scardaci V., Casiraghi C., Lazzeri M., Mauri F., Piscanec S., Jiang D., Novoselov K.S., Roth S. and Geim A.K. // Phys. Rev. Lett. 2006. Vol. 97. P. 187401. DOI:10.1103/PhysRevLett.97.187401

[10] Давыдов В.Ю., Усачёв Д.Ю., Лебедев С.П., Смирнов А.Н., Левицкий В.С., Елисеев И.А., Алексеев П.А., Дунаевский М.С., Вилков О.Ю., Рыбкин А.Г., Лебедев А.А. // ФТП. 2017. Т. 51. С. 11161124. DOI: 10.21883/FTP.2017.08.44800.8559 [Davydov V.Y., Usachov D.Y., Lebedev S.P., Smirnov A.N., Levitskii V.S., Eliseyev I.A., Alekseev P.A., Dunaevskiy M.S., Vilkov O.Y., Rybkin A.G., Lebedev A.A. // Semiconductors. 2017. Vol. 51. P. 1072-1080. DOI: 10.1134/S10 63782617080073]
[11] Panchal V., Pearce R., Yakimova R., Tzalenchuk A., Kazakova O. // Sci. Rep. 2013. Vol. 3. P. 2597. DOI: $10.1038 /$ srep0259

[12] 12Fromm F., Oliveira Jr.M.H., Molina-Sánchez A., Hundhausen M., Lopes J.M.J., Riechert H., Wirtz L., Seyller T. // New J. Phys. 2013. Vol. 15. DOI: $10.1088 / 1367-2630 / 15 / 4 / 043031$ 